\title{
Development and Validation of an HPLC-DAD Method to Quantify Caffeine in Time-release Dosage Forms
}

\author{
SANDRA MARIA RIBEIRO, DENISE BOHRER ${ }^{1,2}$, JÉSSICA LAPINSKI, L. N. DE CARVALHO' ${ }^{1}$, P. T. DO NASCIMENTO ${ }^{1}$ AND \\ CARINE VIANA ${ }^{1 *}$
}

Graduate Program in Pharmaceutical Sciences, Federal University of Santa Maria (UFSM), Santa Maria-RS, ${ }^{1}$ Department of Chemistry, ${ }^{2}$ Center of Health Sciences, UFSM, Santa Maria-RS, Brazil

\section{Ribeiro et al.: An HPLC-DAD Method to Quantify Caffeine in Time-release Dosage Forms}

\begin{abstract}
Controlled release caffeine dosage forms are applied in order improve bioavailability to enhance ergogenic and thermogenic actions. High-performance liquid chromatographic separation was achieved using a C18 reversed phase column, a binary mixture of $0.1 \%$ phosphoric acid and acetonitrile with a flow rate of $0.8 \mathrm{ml} / \mathrm{min}$. UV detection was at $220 \mathrm{~mm}$. Water produced the best extraction efficiency in comparison with other solvents. Retention time observed for caffeine was $4.5 \mathrm{~min}$. The method is selective, reliable, reproducible with a linear range over $1.0-20.0 \mu \mathrm{g} / \mathrm{ml}$ of caffeine $(r>0.9987)$. The proposed method allows to distinguish caffeine from sibutramine, p-octopamine, p-synephrine, tyramine and hordenine. The limit of detection and limit of quantifications were 10 and $30 \mathrm{ng} / \mathrm{ml}$, respectively. The proposed method could be used for the routine analysis of caffeine in time-release dietary supplements.
\end{abstract}

Key words: Caffeine, HPLC-DAD, dietary supplements, time-release dosage forms

Caffeine (1,3,7-trimethylxanthine) is a naturally occurring alkaloid, that can be found in coffee seeds, tea leaves, cocoa and guarana. Its primary function for habitual caffeine consumers is as a central nervous system stimulant ${ }^{[1]}$. Moderate doses of caffeine can improve cognitive function, including vigilance, learning, memory and mood state. When cognitive performance is critical and must be maintained during exposure to severe stress, administration of caffeine may provide a significant advantage ${ }^{[2]}$. Caffeine might also contribute to weight loss by increasing fat oxidation through sympathetic activation of the central nervous system and by acting as a diuretic ${ }^{[3]}$. Moreover, it is the main ingredient in the fat-burner supplements industry, it has benefits on metabolism, thermogenesis and improves performance in low and high intensity exercises $^{[4,5]}$.

Caffeine is the most common stimulant found in dietary supplements, mainly because the low cost and availability of the raw material, which contributes to its high consumption. These supplements are normally used before physical exercise to avoid fatigue and consequently, to improve performance in medium and long-term activities ${ }^{[6]}$. Caffeine's potential effects are thought to be mediated via several mechanisms such

*Address for correspondence E-mail: carineviana@yahoo.com.br

July-August 2019 as antagonism of adenosine receptors, inhibition of phosphodiesterase in skeletal muscle and adipose tissue, release of calcium from intracellular stores, enhancement of sodium/potassium-adenosine triphosphate pump activity leading to a decrease in plasma potassium concentrations, and affect the depolarization-repolarization process during exercise with potential effects on fine motor coordination. Caffeine may also promote increased excitability of the adenosine-sensitive sympathetic nervous system, leading to lipolysis of body fat ${ }^{[7]}$.

The dietary supplements industry is highly innovation driven, aiming mainly to attract the attention of the consumers. New ingredients, technologies and different manufacturing processes have increased in the last few decades. The conventional release oral dosage forms release the drug rapidly after administration. Caffeine's half-life is around $6 \mathrm{~h}$, but its effects in the gradual release system can last up to $10 \mathrm{~h}^{[8]}$. After a loading

This is an open access article distributed under the terms of the Creative Commons Attribution-NonCommercial-ShareAlike 3.0 License, which allows others to remix, tweak, and build upon the work non-commercially, as long as the author is credited and the new creations are licensed under the identical terms

Accepted 21 May 2019

Revised 27 Janauary 2019

Received 20 November 2018

Indian J Pharm Sci 2019;81(4):626-632 
dose, the timed-release dose maintains the caffeine levels in the body over time through a further release of the drug. This technology improves its bioavailability and enhances ergogenic and thermogenic actions ${ }^{[9]}$.

The controlled release dosage forms have at least one component capable of releasing caffeine over time, which is sufficient to maintain plasma concentration over time, while the initially released drug is metabolised ${ }^{[10]}$. These dosage forms might be monolithic or multi-particulate systems. In monolithic systems, the functional release unit is single (tablet or capsule) and the dose is not divided. The multi-particulate pharmaceutical forms contain the drug, which is divided into several functional release subunits, such as granules, pellets or mini-tablets. Multi-particulate systems offer the technological benefit of enabling varied dosages with the same formulation. In addition, it provides biopharmaceutical advantages such as the combination of immediate and controlled release formulations in a single unit, the uniform absorption of caffeine, and a reduced risk of dose dumping. These dosage forms generally have an attractive look and draw the attention of the consumer ${ }^{[11]}$.

In this context, it is necessary to use analytical tools that can quantify caffeine in pharmaceutical formulations, considering the new technologies developed for food supplements. Currently there have been a few studies conducted to quantify caffeine in complex matrices, such as time-release pharmaceutical products. Herein, the analysed dosage forms were comprised of monolithic, such as oily capsules, or multiparticulate systems. The samples of multi-particulate pharmaceutical forms contained caffeine in different functional release subunits, as liquid oil and pellets, in a single unit. Thus, the aim was to develop a method of extraction of caffeine in these dosage forms and quantify them using liquid chromatography reversedphase diode array detection (HPLC-RP-DAD). An official titrimetric assay for caffeine determination in bulk form was applied for comparison.

\section{MATERIALS AND METHODS}

Liquid chromatographic separations were carried out on a Knauer (Berlin, Germany) HPLC system, which consisted of a Smartline Pump 1000 coupled to a Smartline Manager 5000, and a multi-channel UV spectrophotometer detector based on diode array technology (Smartline UV Detector 2600) equipped with ChomGate (Knauer) software (Version 3.3.1). The chromatographic runs were conducted at room temperature $\left(21 \pm 2^{\circ}\right)$ using a reverse-phase $\mathrm{C} 18$ column $(4.6 \times 250 \mathrm{~mm}, 5 \mu \mathrm{m}$; Thermo Scientific, Boston, MA, USA) with an Acclaim $120 \mathrm{C} 18$ guard cartridge. Non-aqueous titration: $\mathrm{pH}$ meter digital Metrohm ${ }^{\circledR}$ 827 pHlab (Suisse) using glass combinate electrode non-aqueous basic-acid titrimetric (solvotrode).

Reference standards of p-octopamine, p-synephrine, tyramine, hordenine and caffeine were purchased from Sigma-Aldrich (Berlin, Germany). All standards were of analytical grade, with at least $98 \%$ purity, and were used without further purification. Sibutramine was pharmaceutical grade and obtained with a certificate of analysis. Acetonitrile (ACN) and orthophosphoric acid ( $85 \%$, w/v) were HPLC grade from Merck, Darmstadt, Germany). Dimethyl sulfoxide (DMSO), methanol and dimethylformamide were analytical grade from Merck (Darmstadt, Germany). Ultra-pure water (Milli-Q Plus, Millipore, Massachusetts, USA) was used to prepare the mobile phase and the solutions. Perchloric acid with $78 \%$ purity was purchased from Vetec (Rio, Brazil). Acetic acid, anhydrous acetic and toluene were purchased from Synth (São Paulo, Brazil).

Phosphoric acid $0.1 \%$ was prepared by transferring $1.180 \mu \mathrm{l}$ of $85 \%$ (w/v) phosphoric acid in a $1000 \mathrm{ml}$ volumetric flask, dissolved in a suitable amount of the Milli-Q water. The eluent was filtered with a cellulose acetate membrane $0.45 \mu \mathrm{m}$. A stock solution of caffeine $(0.5 \mathrm{~g} / \mathrm{l})$ was prepared in methanol, and working solutions were obtained by dilutions of the stock solution with a mobile phase consisting of $0.1 \%$ phosphoric acid and ACN.

Perchloric acid (0.1 M) for non-aqueous titration was prepared as described in the British Pharmacopoeia ${ }^{[12]}$. Gradually, $8.5 \mathrm{ml}$ of perchloric acid was mixed with $900 \mathrm{ml}$ of glacial acetic acid with continuous stirring. After, $20 \mathrm{ml}$ acetic anhydride was added, the volume was made up to $1000 \mathrm{ml}$ in the volumetric flask using glacial acetic acid and left to stand for $24 \mathrm{~h}$ before use.

Caffeine-based supplements were purchased through Brazilian websites. The description of the samples, formulations and dosage form in the food supplements are shown in Table 1. Caffeine extraction efficiency was evaluated through standard recovery tests. The extraction efficiency was investigated with different solvents such as DMSO, dimethylformamide, ACN and water; as well as solvent mixtures in different proportions (20 to $100 \%$ ). The use of ultrasound and the extraction time was also evaluated. 
The samples containing pellets were crushed, dissolved in water $(40 \mathrm{ml})$ and sonicated for $10 \mathrm{~min}$. The solution was filtered with qualitative filter paper. The filtrate was transferred to a $50 \mathrm{ml}$ volumetric flask and the volume was completed with a mobile phase. The content of the oily capsules was carefully transferred to a $50 \mathrm{ml}$ volumetric flask and the volume was completing with a mobile phase. All extracts were diluted 1000fold in a mobile phase and filtered through a $0.45 \mu \mathrm{m}$ cellulose acetate membrane before injection in to the chromatographic system. All samples were analysed by HPLC-DAD in triplicate.

\section{Non-aqueous titration:}

The content of the capsules was carefully transferred to a $150 \mathrm{ml}$ glass beaker. The samples containing pellets in their formulation were crushed and homogenised. After addition of $5 \mathrm{ml}$ of acetic anhydride $\mathrm{R}$, the samples were heated to $50^{\circ}$ until complete dilution. After cooling, $10 \mathrm{ml}$ of acetic anhydride $\mathrm{R}$ and $20 \mathrm{ml}$ of toluene $\mathrm{R}$ were added and the titration was performed.

\section{Chromatographic conditions:}

Chromatographic runs were conducted at room temperature $\left(21 \pm 2^{\circ}\right)$ on a C18 column (Thermo Scientific) $(4.6 \times 250.0 \mathrm{~mm})$, particle size $5.0 \mu \mathrm{m}$. The mobile phase composition of $0.1 \%$ phosphoric acid:ACN (70:30 v/v), pH 2.0 \pm 0.1 adjusted with orthophosphoric acid. The mobile phase was filtered using $0.45 \mu \mathrm{m}$ membrane filters and degassed by ultrasonic vibrations for $30 \mathrm{~min}$ prior to use. The flow rate was $0.8 \mathrm{ml} / \mathrm{min}$ and the injection volume was $20 \mu \mathrm{l}$. The re-equilibration period of 5 min was used between individual runs. Before the daily chromatographic experiments, the $\mathrm{C} 18$ column was conditioned with the mobile phase for $1 \mathrm{~h}$. The detection was performed at $220 \mathrm{~nm}$. Samples were titrated with $0.1 \mathrm{M}$ perchloric acid, determining the end-point potentiometrically. One millilitre of $0.1 \mathrm{M}$ perchloric acid is equivalent to $19.42 \mathrm{mg}$ of caffeine $\left(\mathrm{C}_{8} \mathrm{H}_{10} \mathrm{~N}_{4} \mathrm{O}_{2}\right)^{[12]}$.

\section{Validation parameters:}

The HPLC-DAD method was validated according to the following parameters: linearity, specificity, limit of detection (LOD) and limit of quantification (LOQ), precision and accuracy ${ }^{[13,14]}$. The linear range for caffeine was evaluated by injection of six concentration levels and three different days. The calibration curve was performed in a concentration level, which was prepared from the stock solution within the linear range obtained for the caffeine and described in Table 2. The sensitivity was calculated using the LOD and LOQ following Eqn., $\mathrm{LOD}=3.3 \times \mathrm{Sa} / \mathrm{b}$ and $\mathrm{LOQ}=10 \times \mathrm{Sa} / \mathrm{b}$, were $\mathrm{Sa}$ is the intercept standard deviation (SD) and $\mathrm{b}$ is the slope. SD was obtained by seven measurements of the background noise. The precision of the method was determined by the assay repeatability (intraday precision) and intermediate precision (inter-day precision) and the results expressed as relative standard deviation (RSD) of a series of measurements. To evaluate the precision (repeatability test), six triplicates were analysed from the same sample feed supplement containing caffeine at a concentration corresponding to $5.88 \mathrm{mg} / \mathrm{l}$ where $3.88 \mathrm{mg} / \mathrm{l}$ of caffeine was already contained in the capsule analysed and $2.0 \mathrm{mg} / \mathrm{l}$ was added to reach their concentration. The data for the intermediate precision were collected on different days $(n=3)$. The accuracy was evaluated as the percentage of recovery obtained from analysing samples spiked with known amounts of reference substance at a fixed concentration level. Accuracy was expressed by the recovery results obtained in triplicate for the following concentration levels for caffeine reference substance, $5.0,10.0$ and $15.0 \mathrm{mg} / 1$. The $\%$ recovery was calculated using the formula proposed by AOAC ${ }^{[13]}$. Sibutramine, caffeine, p-octopamine, p-synephrine, tyramine and hordenine were tested as interfering in the method specificity test. These bulk raw materials were treated in the same way as the samples.

The non-aqueous titration was validated by determination of the operational characteristics' precision and accuracy ${ }^{[13]}$. The precision of the method was determined by intra-day precision and inter-day precision and the results were expressed as RSD of a series of measurements. To evaluate the precision, 6 triplicates were analysed from the same sample, on the same day and under the same experimental conditions and the intermediate precision were collected on different days $(n=3)$. Accuracy was expressed by the recovery results obtained in triplicate for the following concentration levels for caffeine reference substance, 50,75 and $100 \mathrm{mg} / \mathrm{l}$. The \% recovery was calculated using the formula proposed by AOAC ${ }^{[13]}$.

\section{RESULTS AND DISCUSSION}

The reported methods for determining caffeine apply liquid-liquid extraction, solid phase extraction, supercritical fluid extraction, ultrasound, microwave and solvents for caffeine extraction ${ }^{[5,14-17]}$. However, there is still no official method of extraction and quantification of caffeine in oily matrices or time- 


\begin{tabular}{|c|c|c|c|c|c|c|}
\hline \multirow{2}{*}{ Sample } & \multirow{2}{*}{ Dosage form } & \multirow{2}{*}{ Release } & \multirow{2}{*}{$\begin{array}{c}\text { Labeled } \\
\text { caffeine } \\
\text { (mg/capsule) }\end{array}$} & \multirow{2}{*}{ Excipients } & \multicolumn{2}{|c|}{ Given caffeine $(\% \pm R S D)$} \\
\hline & & & & & HPLC-DAD ${ }^{1}$ & Volumetry $^{2}$ \\
\hline A & $\begin{array}{l}\text { Hard gelatin capsule } \\
\text { containing two- } \\
\text { phases: oil/solid } \\
\text { (pellets) }\end{array}$ & $\begin{array}{l}\text { Time } \\
\text { release }\end{array}$ & 143 & $\begin{array}{l}\text { Medium chain triglycerides (MCT), } \\
\text { alpha-tocopherol antioxidant, } \\
\text { gelatin, silicon dioxide, dyes }\end{array}$ & $94.4 \pm 2.6$ & $101.7 \pm 2.5$ \\
\hline B & $\begin{array}{l}\text { Hard gelatin capsule } \\
\text { containing two- } \\
\text { phases: oil/solid } \\
\text { (pellets) }\end{array}$ & $\begin{array}{l}\text { Time } \\
\text { release }\end{array}$ & 140 & Safflower Oil & $106.8 \pm 4.1$ & $102.9 \pm 1.0$ \\
\hline C & $\begin{array}{l}\text { Hard gelatin capsule } \\
\text { containing two- } \\
\text { phases: oil/solid } \\
\text { (pellets) }\end{array}$ & $\begin{array}{l}\text { Time } \\
\text { release }\end{array}$ & 143 & $\begin{array}{l}\text { Sesame oil, silicone dioxide, titanium } \\
\text { dioxide, dyes }\end{array}$ & $100.5 \pm 4.8$ & $103.9 \pm 0.9$ \\
\hline D & $\begin{array}{l}\text { Hard gelatin capsule } \\
\text { containing two- } \\
\text { phases: oil/solid } \\
\text { (pellets) }\end{array}$ & $\begin{array}{l}\text { Time } \\
\text { release }\end{array}$ & 97 & $\begin{array}{l}\text { Iphoric potent methyl B-PEA matrix } \\
\text { (105 mg), Polygonum cuspidatum, } \\
\text { Huperzia serrata, Coryanthe } \\
\text { yohimbe, Hordeum vulgare, } \\
\text { isopropyloctopamine, 3'-5'-cyclic } \\
\text { adenosine monophosphate, } \\
\text { 1,3-n-dipropyl-7-propargylxanthine, } \\
\text { olive leaf extract, MCT, lactose } \\
\text { anhydrous, talc, croscarmellose } \\
\text { sodium, magnesium stearate, calcium } \\
\text { silicate, gelatin, titanium dioxide, } \\
\text { polysorbate 80, hypromellose, } \\
\text { polydextrose, ethylcellulose, } \\
\text { ammonium hydroxide, polyethylene } \\
\text { glycol, magnesium silicate, oleic } \\
\text { acid, triacetin, dyes }\end{array}$ & $104.4 \pm 3.3$ & na \\
\hline E & Hard gelatin capsule & $\begin{array}{l}\text { Immediate } \\
\text { release }\end{array}$ & 210 & $\begin{array}{l}\text { Soybean oil, vegetable oil emulsifier, } \\
\text { soy lecithin }\end{array}$ & $85.6 \pm 3.8$ & $89.7 \pm 1.4$ \\
\hline $\mathbf{F}$ & Soft gelatin capsule & $\begin{array}{l}\text { Immediate } \\
\text { release }\end{array}$ & 210 & $\begin{array}{c}\text { Sesame oil, hydroxypropyl } \\
\text { methylcellulose, titanium dioxide, } \\
\text { dyes }\end{array}$ & $85.7 \pm 3.8$ & $86.0 \pm 1.9$ \\
\hline
\end{tabular}

Commercial dosage forms, type and composition along with the label claim of caffeine content were analyzed using HPLC-DAD method and anhydrous volumetry. ${ }^{1} n=3 ;{ }^{2} n=12$; na= not analyzed

release dosage forms. Therefore, this study aimed to propose a simple, economical and rapid extraction method for quantification of caffeine present in these pharmaceutical forms. It was investigated with different solvents such as DMSO, dimethylformamide, $\mathrm{ACN}$ and water; as well solvent mixtures in different proportions (20 to $100 \%$ ). The extraction efficiency was evaluated through standard recovery tests.

The mixture of $60 \%$ DMSO in methanol showed a good dissolution of caffeine in the samples. However, the percentage of caffeine recovery was not adequate, varying from 38.09 to $66.0 \%$. Due to the polarity of caffeine and its solubility in water $\left(21.6 \mathrm{~g} / 1 \text { at } 25^{\circ}\right)^{[18]}$, this solvent was tested. The extraction efficiency of the water ranged from 95.2 to $104.7 \%$, and they were within the established value for dietary supplements between 80 and $120 \%{ }^{[13]}$. The extraction time was also evaluated from 5 to $30 \mathrm{~min}$. The sonication during 10 min was the appropriate time for extraction of the samples.

A HPLC-DAD method was performed for a successful separation, identification and quantification of caffeine in oily capsules and in time-release pharmaceutical products. The retention time observed for caffeine was $4.5 \mathrm{~min}$. The external calibration curves were constructed with standard caffeine using six levels of increments in triplicate. The method showed good linearity $\left(r^{2}>0.9993\right)$ in the range of concentrations studied (1.0-20.0 $\mu \mathrm{g} / \mathrm{ml})$. The analysis of variance (ANOVA) showed a significant linear regression and no deviation from linearity $(\mathrm{p}<0.05)$. The sensitivity of the chromatographic system employed was assessed by determining the limits of detection and quantification. The results were 0.01 and $0.03 \mu \mathrm{g} / \mathrm{ml}$, respectively, 
these were considered as low and demonstrated a good sensitivity for the method.

The interferents, sibutramine, caffeine, p-octopamine, p-synephrine, tyramine and hordenine did not affect the caffeine determination by the proposed HPLCDAD method, since they presented distinct retention times (fig. 1). The method specificity can be also ensured by the purity of the chromatographic peak, through the absorption spectrum that is generated for each compound from the diode arrangement detector.

The repeatability and intermediate precision were estimated by variation coefficients expressed by the RSD of the results obtained in triplicate for a fixed concentration level of $5.88 \mu \mathrm{g} / \mathrm{ml}$. It was observed in all tests that the method, in addition to presenting consistent results within the limits established by current legislation, also showed low variation coefficients, indicating a high level of precision of the method. The accuracy was calculated as the percentage of recovery by known added amounts of caffeine $(1.0,5.0$ and $15.0 \mu \mathrm{g} / \mathrm{ml})$ in the capsule solution. Each solution was prepared in triplicate. The results were acceptable because they were in the range of 96.2 to $98.1 \%$, indicating that this assay was accurate. The low percentage of RSD obtained for all samples analysed and added standard indicate good accuracy and repeatability. The results obtained are presented in Table 2 and fig. 2 shows the chromatogram obtained by the proposed HPLC-DAD method for sample ' $F$ ' spiked with caffeine standard (10 ppm).

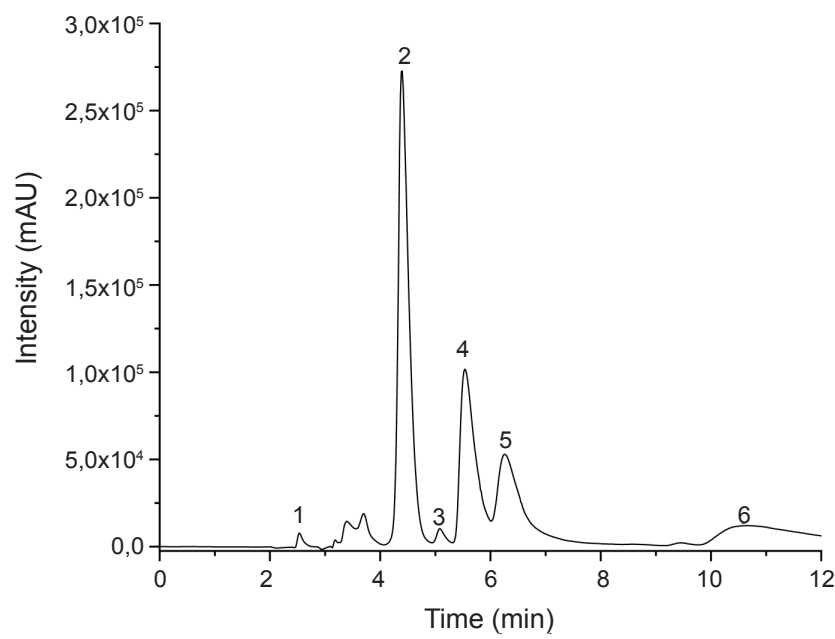

Fig. 1: Chromatograms of reference standards obtained by the proposed HPLC-DAD method

All standard substances, 1. sibutramine, 2. caffeine, 3. p-octopamine, 4. p-synephrine 5. tyramine and 6. hordenine were at $50 \mu \mathrm{g} / \mathrm{ml}$. Mobile phase- $0.1 \%$ phosphoric acid/ACN, flow rate was $0.8 \mathrm{ml} / \mathrm{min}$ and $\mathrm{UV}$ detection at $220 \mathrm{~nm}$

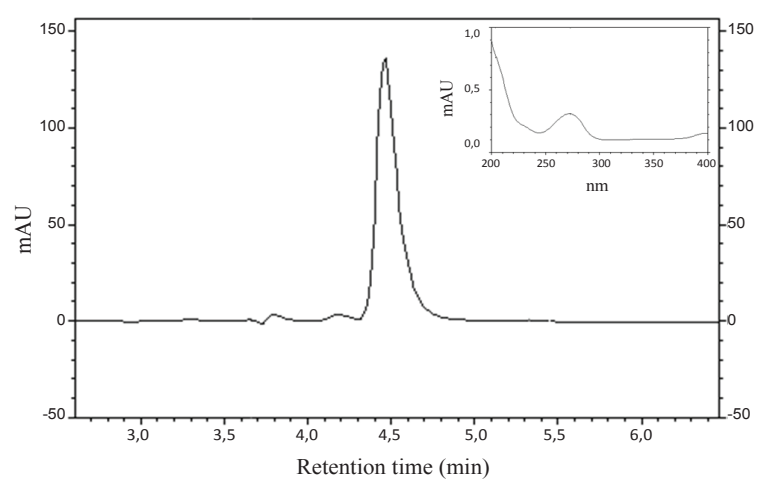

Fig. 2: Chromatogram of sample $F$ obtained by the proposed HPLC-DAD method

Sample ' $F$ ' spiked with caffeine standard $(10 \mathrm{ppm})$ was analysed using HPLC-DAD method. Sample composition is as described in Table 1. Mobile-phase- $0.1 \%$ phosphoric acid/ACN, flow rate was $0.8 \mathrm{ml} / \mathrm{min}$ and $\mathrm{UV}$ detection at $220 \mathrm{~nm}$

TABLE 2: CHARCTERISTICS OF HPLC-DAD METHOD FOR CAFFEINE DETERMINATION

\begin{tabular}{lc}
\hline Parameters & Results $^{\mathrm{a}}$ \\
\hline Concentration range $(\mu \mathrm{g} / \mathrm{ml})$ & $1.0-20.0$ \\
Slope \pm standard error & $140361 \pm 2247$ \\
Intercept \pm standard error & $-45252 \pm 23338$ \\
Correlation coefficient $(\mathrm{r})$ & 0.9993 \\
Analysis of variance & \\
Linear regression & $11464.56(4.41)^{\mathrm{b}}$ \\
Linearity deviation & $2.66(2.93)^{\mathrm{c}}$ \\
Limits & \\
LOD $(\mu \mathrm{g} / \mathrm{ml})$ & 0.01 \\
LOQ $(\mu \mathrm{g} / \mathrm{ml})$ & 0.03 \\
Precision $(\mathrm{RSD})$ & \\
Intra day & \\
Day $1(\mathrm{n}=6)$ & 1.9 \\
Day $2(\mathrm{n}=3)$ & 1.6 \\
Day $3(\mathrm{n}=3)$ & 1.5 \\
Inter day & 1.7 \\
Recovery test & \\
Added $(\mu \mathrm{g} / \mathrm{ml})$ & Recovery $(\% \pm R S D)$ \\
$5(\mathrm{n}=3)$ & $98.1 \pm 1.2$ \\
$10(\mathrm{n}=3)$ & $96.2 \pm 2.0$ \\
$15(\mathrm{n}=3)$ & $97.2 \pm 1.9$ \\
Mean & 97.1 \\
\hline aData obtained from 3 six-point calibration & curves. ${ }^{\text {VValues in }}$ \\
parentheses are the corresponding critical values for $F$ at $\mathrm{p}=0.05$. \\
cValues in parentheses are the corresponding critical values for $F$ \\
at $\mathrm{p}=0.10$
\end{tabular}

The caffeine-containing products selected in this study have a time-release technological differential. The six samples were oily capsules or hard capsules containing two phases (oily liquid plus time-release pellets). Pictures of the analysed dosage forms are shown in fig. 3 .

Samples A, B, C and D analysed in this work were multi-particulate systems containing caffeine carried in hard gelatine capsules. The caffeine was present in 
two functional release subunits, a liquid oil and pellets. The caffeine from the oily phase is immediately absorbed after ingestion of the capsule. The pellets with caffeine allow at least about 20 to $50 \%$ by weight of the stimulant from the composition within about $2 \mathrm{~h}$ after administration, and releasing the balance of the stimulant within about 8 to $10 \mathrm{~h}$ after administration ${ }^{[19]}$. The oily liquid phase is generally composed of fixed oils, such as medium chain triglycerides and oils from soybean, sesame and safflower. Such ingredients were labelled as described in Table 1.

The formulation $\mathrm{E}$ is an emulsified system and product $\mathrm{F}$ is a suspension in the form of soft gelatine capsules. The excipients used in these dosage forms are oily liquids, gelling agents and emulsifiers (Table 1). Unlike time-release technology, the caffeine present in these products is absorbed immediately into the body. Samples E and F presented content, which did not correspond to the value declared on the label. Other authors also found caffeine contents not recommended: 27 to $113 \%{ }^{[20]}$; 0 to $226 \%{ }^{[21]}$; and about $70 \%$ of value declared $^{[22]}$.

A

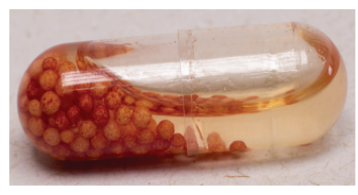

B

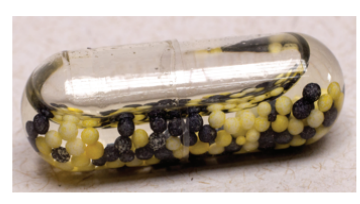

C

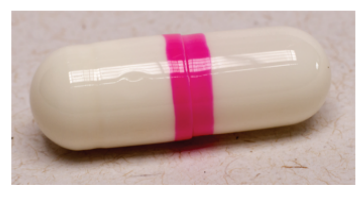

D

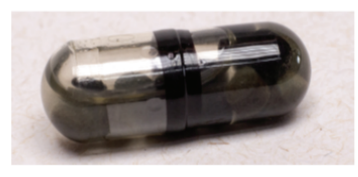

E

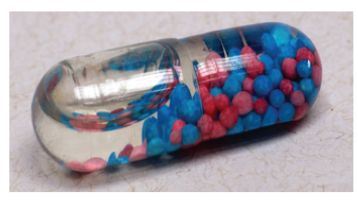

$\mathbf{F}$

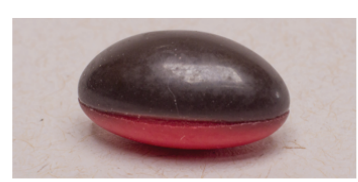

Fig. 3: Dietary supplements analyzed in this study

Caffeine can be estimated by using non-aqueous methods. The use of simple reagents with minimum sample preparation allows the method to be used for routine analysis and quality control assays of caffeine in pharmaceutical forms. Nevertheless, there is no official method for caffeine determination in oily capsules and for time-release dosage forms. Therefore, the official titrimetric assay for caffeine determination in bulk form recommended by the British Pharmacopoeia ${ }^{[12]}$ was applied. Accuracy, intra-day and inter-day precision were evaluated. The RSD values of intra and inter-day precision obtained in triplicate were all below 2.3. The accuracy results ranged from 95.6 to $100.2 \%$. The statistical analysis (ANOVA) of the results obtained from volumetric and chromatographic methods didn't present a significant difference $(\mathrm{p}<0.05$; Table 1$)$.

The volumetric method presented interferences from the matrix, once the end-point cannot be determined in the sample D. A large amount of ingredients, excipients, vegetable materials and dyes in its composition can be the probable reason. However, it was not specifically determined which of the ingredients interfered in the quantification of caffeine by the method.

The proposed HPLC-DAD method allowed for caffeine determination in products with a timerelease technological differential. A simple extraction method of caffeine using water as a solvent coupled to sonication was effective for determination. The results obtained in linearity, specificity, LOD, LOQ, accuracy and precision were suitable. The proposed method permits a fast and sensitive way to distinguish caffeine from sibutramine, caffeine, p-octopamine, p-synephrine, tyramine and hordenine. The available analytical method, simple and economical, can contribute to the quality and regulatory control of these dietary supplements.

\section{Acknowledgements:}

The authors wish to acknowledge the financial support given by the Brazilian foundations CNPq and CAPES.

\section{Conflict of interest:}

All authors declare no conflicts of interest.

\section{Financial assistance/scholarship:}

This study was supported by the Brazilian foundations National Council for Scientific and Technological Development (CNPq). 


\section{REFERENCES}

1. Institute for Health Metrics and Evaluation. The vast majority of American adults are overweight or obese, and weight is a growing problem among US children. [cited 2018 Oct 5]. Available from: http://www.healthdata.org/news-release/ vast-majority-american-adults-are-overweight-or-obese-andweight-growing-problem-among.

2. Brazil. Ministério da Saúde. Departamento de Vigilância de Doenças e Agravos não transmissíveis e Promoção da Saúde. Vigitel Brasil: vigilância de fatores de risco para doenças crônicas por inquérito telefônico. Brasília: MS. [cited 2018 Oct 10]. Available from: http://portalarquivos.saude.gov.br/ images/pdf/2017/junho/07/vigitel_2016_jun17.pdf.

3. National Institute of Health. Office of Dietary Supplements. Health Professional Dietary Supplements of Weigth Loss. [cited 2018 Oct 10]. Available from: https://ods.od.nih.gov/ factsheets/WeightLoss-HealthProfessional/.

4. Gurley BJ, Steelman SC, Thomas SL. Multi-ingredient, caffeine-containing dietary supplements: History, safety and efficacy. Clin Ther 2015;37(2):275-301.

5. Lieberman HR, Tharion WJ, Shukitt-Hale B, Speckman KL, Tulley R. Effects of caffeine, sleep loss and stress on cognitive performance and mood during U.S. navy SEAL training. Psychopharmacology 2002;164(3):250-61.

6. Yen M, Ewald MB. Toxicity of weight loss agents. J Med Toxicol 2012;8(2):145-52.

7. Astrup A, Toubro S, Cannon S, Hein P, Breum L, Madsen J. Caffeine: a double blind, placebo-controlled study of its thermogenic, metabolic, and cardiovascular effects in healthy volunteers. Am J Clin Nutr 1990;51(5):759-67.

8. Viana C, Zemolin GM, Müller LS, Dal Molin TR, Seiffert H, de Carvalho LM. Liquid chromatographic determination of caffeine and adrenergic stimulants in food supplements sold in Brazilian e-commerce for weight loos and physical fitness. Food Addit Contam Part A Chem Anal Control Expo Risk Assess 2016;33(1):1-9.

9. Almeida C, Sangiovanni D, Liberali R. Cafeína: efeitos ergogênicos nos exercícios físicos. Rev Bras Nutr Esport 2009;3:198-209.

10. Institute of Medicine. Committee on Military Nutrition Research. Caffeine for the Sustainment of Mental Task
Performance: Formulations for Military Operations. Washington (DC): National Academies Press (US), 2001. [cited 2018 Oct 10]. Available from: https://www.ncbi.nlm. nih.gov/books/NBK223799/.

11. Chauffard F, Enslen MYA, Tachon P. Sustained release microparticulate caffeine formulation. United States patent US08357689. 1994 Dec 16.

12. The British Pharmacopoeia. London: Stationery Office: British Pharmacopoeia Commission; 2010.

13. Appendix K: Guidelines for Dietary Supplements and Botanicals. AOAC Official methods, 2013. Available from: http://www.eoma.aoac.org/app_k.pdf.

14. United States Pharmacopoeia (USP). 39th ed. Rockville, Maryland: United States Pharmacopeial Convention, Inc.; 2016.

15. Evans RL, Siitonen PH. Determination of Caffeine and Sympathomimetic Alkaloids in Weigth Loos Supplements by High-Performance Liquid Chromatography. J Chromatogr Sci 2008;46(1):61-67.

16. De Carvalho LM, Cohen PA, Silva CV, Moreira AP, Falcão TM, Dal Molin TR, et al. A new approach to determining pharmacologic adulteration of herbal weight loss products. Food Addit Contam Part A Chem Anal Control Expo Risk Assess 2012;29(11):1661-7.

17. Patil PN. Caffeine in various samples and their analysis with HPLC - A Review. Int J Pharm Sci Rev Res 2012;18:76-83.

18. Viana C, Zemolin GM, Lima FO, de Carvalho LM, Bottoli CB, Limberger RP. High-performance liquid chromatographic analysis of biogenic amines in pharmaceutical products containing Citrus aurantium. Food Addit Contam Part A Chem Anal Control Expo Risk Assess 2013;30(4):634-42.

19. National Center for Biotechnology Information - NCBI (2017). Pubchem Compound Database; CID=2519. [cited 2018 Oct 12]. Available from: https://pubchem.ncbi.nlm.nih. gov/compound/2519.

20. Shargel L, Wu-Pong S, Yu ABC. Applied Biopharmaceutics \& Pharmacokinetics. $6^{\text {th }}$ ed. USA: McGraw-Hill Medical; 2012. p. 469-503.

21. Vepuri K, Uppugalla NR. Controlled release caffeine dosage forms. United States patent 20160128943 A1. 2016 May 12.

22. Brockman R, Gorman JM. Time Released Caffeine. United States patent 20160367559 A1. 2016 Apr 21. 